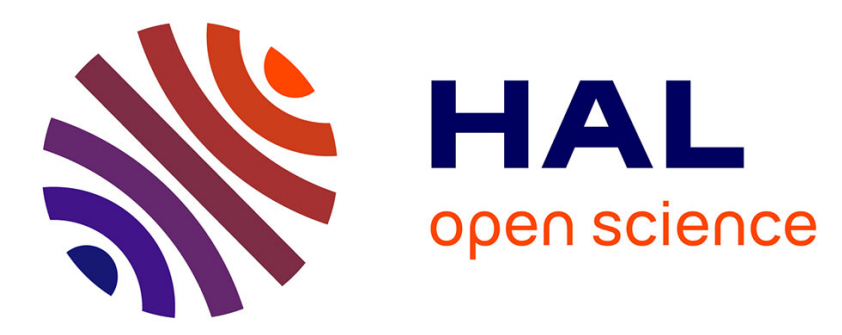

\title{
Influence of sampling strategies on the monitoring of cyanobacteria in shallow lakes: Lessons from a case study in France
}

David Pobel, Joël Robin, Jean-François Humbert

\section{- To cite this version:}

David Pobel, Joël Robin, Jean-François Humbert. Influence of sampling strategies on the monitoring of cyanobacteria in shallow lakes: Lessons from a case study in France. Water Research, 2011, 45 (3), pp.1005-1014. 10.1016/j.watres.2010.10.011 . bioemco-00551032

\section{HAL Id: bioemco-00551032 \\ https://hal-bioemco.ccsd.cnrs.fr/bioemco-00551032}

Submitted on 1 Jan 2011

HAL is a multi-disciplinary open access archive for the deposit and dissemination of scientific research documents, whether they are published or not. The documents may come from teaching and research institutions in France or abroad, or from public or private research centers.
L'archive ouverte pluridisciplinaire HAL, est destinée au dépôt et à la diffusion de documents scientifiques de niveau recherche, publiés ou non, émanant des établissements d'enseignement et de recherche français ou étrangers, des laboratoires publics ou privés. 
1 Influence of sampling strategies on the monitoring of cyanobacteria in 2 shallow lakes: lessons from a case study in France

3

4 David Pobel $^{1}$, Joël Robin ${ }^{1}$ and Jean-François Humbert ${ }^{2}$

5 1- ISARA-Lyon, Equipe Ecosystèmes et Ressources Aquatiques, 23 rue Jean Baldassini 69364 Lyon Cedex 07,

6 France

7 2- INRA, UMR 7618 BIOEMCO, Site de l'ENS, 46 rue d’Ulm, 75005 Paris, France

8 Corresponding author: J.F. Humbert

9 


\section{Abstract}

10 Sampling cyanobacteria in freshwater ecosystems is a crucial aspect of monitoring programs

11 in both basic and applied research. Despite this, few papers have dealt with this aspect, and a

12 high proportion of cyanobacteria monitoring programs are still based on monthly or twice-

13 monthly water sampling, usually performed at a single location. In this study, we conducted

14 high frequency spatial and temporal water sampling in a small eutrophic shallow lake that experiences cyanobacterial blooms every year. We demonstrate that the spatial and temporal aspects of the sampling strategy had a considerable impact on the findings of cyanobacteria monitoring in this lake. In particular, two peaks of Aphanizomenon flos-aquae cell abundances were usually not picked up by the various temporal sampling strategies tested. In contrast, sampling once a month was sufficient to provide a good overall estimation of the population dynamics of Microcystis aeruginosa. The spatial frequency of sampling was also important, and the choice in the location of the sampling points around the lake was very important if only two or three sampling points were used. When four or five sampling points were used, this reduced the impact of the choice of the location of the sampling points, and allowed to obtain fairly similar results than when six sampling points were used. These findings demonstrate the importance of the sampling strategy in cyanobacteria monitoring, and the fact that it is impossible to propose a single universal sampling strategy that is appropriate for all freshwater ecosystems and also for all cyanobacteria.

Keywords: sampling strategy, cyanobacteria, spatiotemporal dynamic, Microcystis aeruginosa, Aphanizomenon flos-aquae 


\section{$31 \quad 1$ Introduction}

32 Due to eutrophication and, to a lesser extent, to climatic changes (Markensten et al., 2010;

33 Paerl and Huisman, 2009) cyanobacterial blooms seem to be increasing in freshwater ecosystems worldwide. These blooms severely disrupt the functioning of these ecosystems and potential water use. Furthermore, many cyanobacterial species are able to produce a variety of toxic metabolites, which can be harmful to both human (Kuiper-Goodman et al., 1999) and animal (Codd et al., 2005) health. For these reasons, numerous attempts have been made in the last 20 years to elucidate the factors that control cyanobacterial blooms and toxin production, and thus to make it possible to evaluate better the health risks associated with bloom events. From all these studies, it is clear that the spatial distribution of cyanobacteria in freshwater ecosystems can display marked horizontal and vertical variations (Porat et al., 2001; Welker et al., 2003). Moreover, by means of a real time PCR analysis of a gene involved in the biosynthesis of microcystins we have shown that considerable fluctuations can also occur in the proportions of potentially microcystin-producing and non-producing cells during the course of Microcystis aeruginosa blooms (Briand et al., 2009). Similar results have been found for various different $M$. aeruginosa populations located in the same geographic area (Sabart et al., 2009), which makes it difficult to manage the health risks associated with these events.

All these studies indicate that the sampling strategy used for monitoring cyanobacteria is a critical aspect, both in basic research on cyanobacteria, (e.g. investigation of the factors and processes involved in the development of the blooms), and in applied research, (e.g. implementing monitoring programs of these microorganisms in freshwater ecosystems used to provide drinking water or for recreational activities). In recent years, new tools have been tested with the intention of improving cyanobacterial sampling, for example, remote sensing 
reconnaissance to determine the horizontal distribution of cyanobacteria in freshwater ecosystems (Hunter et al., 2009), or spectrofluorometric probes to reveal the vertical distribution of these cyanobacteria in the water column (Leboulanger et al., 2002). Moreover, these spectrofluorometric probes and other sensors have now been integrated into buoys, to provide real-time monitoring of cyanobacteria in freshwater ecosystems (Le Vu et al., in press).

However, despite the great potential interest of these tools, their cost will remain prohibitive for their routine use in the foreseeable future, and most of the monitoring programs worldwide for the survey of cyanobacteria will continue to be based on more conventional methods for some years to come. Taking discrete samples of various volumes of water taken from the shoreline of ecosystems is probably the method one most often used in studies. Unfortunately, as a result of spatial and temporal differences in the distribution of cyanobacteria, this approach can often provide a very poor estimation of cyanobacterial abundance and, consequently, of the associated health risk. We therefore need to devise simple sampling strategies for the low cost monitoring of cyanobacteria in shallow lakes. In an attempt to do this, we performed intense spatiotemporal monitoring of cyanobacteria in a shallow lake known to experience cyanobacterial blooms every year.

\section{Materials \& Methods}

\subsection{Study site}

This study was performed in a shallow lake named Place $\left(0.08 \mathrm{~km}^{2}, 2.5 \mathrm{~m}\right.$ max depth, $\left.45^{\circ} 43^{\prime} \mathrm{N}, 4^{\circ} 14^{\prime} \mathrm{E}\right)$ located in the plain of Forez (Central France), (Fig. 1). This lake is used for extensive fish production and its trophic status is eutrophic to hypereutrophic (OCDE, 1982). Microcystis aeruginosa blooms occur every summer. 


\subsection{Data acquisition}

\subsubsection{Sampling strategy and cell counting}

In order to assess the variations in the horizontal distribution of cyanobacteria in this pond, we monitored six sampling points located around the lake at one meter from the shore (V1-V6; Fig. 1). The water depth in each of these sampling points was around 1 meter. Samples were taken every two days, between 09:00 and 10:00 a.m., from early June 2008 to early October 2008. The first 40 -centimeters of the water column were sampled using a watersampler (Uwitech, Austria). This water sample was shacked and then divided into two 1-L bottles, one liter being stored at room temperature with Lugol's iodine solution, and the other at $4{ }^{\circ} \mathrm{C}$. In order to evaluate the vertical distribution of cyanobacteria in the water column, we performed a 22-hour survey (from 4:30 p.m. August 4, 2009 to 2:30 p.m. August 5, 2009), of the variations of cyanobacterial biomass at five sampling points (A-E; Fig. 1) using a BBE Algaetorch (Moldaenke, Germany). This torch is based on the same principle as the BBE spectrofluorometric probe (Beutler et al., 2002), but provides only an estimation of the concentrations of cyanobacteria and total chlorophyll in water. Every hour, the torch was immersed to a depth of 20 centimeters at the five sampling points, and triplicate measurements were performed in each point.

The cyanobacterial cell concentrations were estimated using a Nageotte cell and an optical microscope, as described in Brient et al. (2008). For each rectangular area, we counted at least 400 cells of each cyanobacterial species.

\subsubsection{Meteorological data}

102 The speed and direction of wind during our study were obtained from the Metéo France 103 meteorological station at St Etienne-Bouthéon $\left(4^{\circ} 18^{\prime} \mathrm{E}-45^{\circ} 32^{`} \mathrm{~N}\right)$. The wind direction rose 
104 for this station is given in Supplemental Figure 1, and shows that the two dominant wind

105 directions were NW and SE. The direction of winds blowing from $240^{\circ}-60^{\circ}$ was classified 106 as NW, and that of winds blowing from $60^{\circ}-240^{\circ}$ as SE.

\subsection{Data analysis}

109 The spatial distribution of cyanobacteria in the lake was represented using Surfer (v. 7.0,

110 Golden Software Inc.), and statistical analyses (Wilcoxon test, Spearman correlation) were 111 performed using the $\mathrm{R}$ package version 2.10 ( $\mathrm{R}$ development core Team, 2010).

\section{Results}

\subsection{Change over time in the population dynamics of the two dominant cyanobacterial}

115 species

116 Two cyanobacterial species, Microcystis aeruginosa and Aphanizomenon flos-aquae,

117 dominated the phytoplankton community during the summer of 2008 . The population

118 dynamics of these two species displayed very contrasting patterns (Fig. 2). The population

119 dynamics of Microcystis aeruginosa was characterized by a steady increase in the cell

120 abundance from June to August, apart from a brief dip in the middle of July. The maximum

121 population was reached on August $21(264,000$ cells $/ \mathrm{mL})$, and subsequently the cell

122 concentration remained stable until the end of September, and then decreased in October. In

123 contrast, the population dynamics of Aphanizomenon flos-aquae were much more chaotic,

124 with the cell abundance reaching two very high and short-lived peaks in July

125 (400,000 cells/mL on July 17 , and 560,000 cells/mL on July 23$)$. 
128 Our assessment of the changing population dynamics of the two cyanobacteria were obtained

129 using a very frequent high temporal sampling regime (every two days), which would not be

130 practicable in the context of normal monitoring programs. In order to evaluate the impact of

131 the sampling frequency, we simulated weekly, twice-monthly and monthly sampling

132 frequencies to our data set. The results of these simulations are shown in Fig. 3 and 4. From

133 this figure, we can see that changes in M. aeruginosa cell abundance over time would have

134 been fairly accurately estimated at all these sampling frequencies. Moreover, for all sampling

135 frequencies, the quality of the estimation of the $M$. aeruginosa population dynamics was not

136 influenced by choice of the first sampling date (Fig. 3). In contrast, the population dynamics

137 of $A$. flos-aquae would have been badly or even very badly estimated by using weekly, twice-

138 monthly and monthly sampling frequencies (Fig. 4). We would only have detected both

139 A. flos-aquae peaks in one of the three trials testing the weekly sampling strategy, and we

140 would never have detected these peaks with twice-monthly and monthly sampling

141 frequencies.

$143 \quad 3.3$ Evolution of the horizontal distribution of cyanobacteria in the lake during the

\section{4 bloom}

145 As shown in the video (Supplemental Fig. 2), the horizontal distribution of both cyanobacteria

146 displayed marked variations during the course of the study. Moreover, when the spatial

147 distributions of the two species at the same sampling dates were compared, it could be seen

148 that similar or contrasting patterns in the horizontal distribution of M. aeruginosa and A. flos-

149 aquae cells would have been found, depending on the dates chosen (some examples are 150 provided in Fig. 5).

151 In order to obtain a better picture of this spatial variability in the cell concentrations of

152 the two species, we estimated the coefficients of variation in the mean abundance for each 
sampling date and for each species from the results obtained at the six sampling points

(Fig. 6). These coefficients were usually higher for A. flos-aquae than for M. aeruginosa

(Wilcoxon test, $\mathrm{p}=-3.25 \cdot 10^{-05}$ ), suggesting that the horizontal distribution of $A$. flos-aquae was more variable. Finally, there was no correlation (Spearman coefficient) between the coefficient of variation and the mean cell abundance for Aphanizomenon, and only a weak correlation was found for Microcystis (Spearman coefficient, $\mathrm{p}=0.003 \mathrm{r}=-0.4$; Supplemental Fig. 3).

In order to find out whether wind speed/direction could account for the variations in the horizontal distribution of cyanobacterial cell abundance in the lake, we recorded in a first time, for each species and for each sampling date, the sampling point (out of the six) at which the highest cell abundance was detected. We then constructed a table in which we related these findings to the wind direction and speed in the five hours before the sampling, knowing that only data with wind speed values $\geq 2.0 \mathrm{~m} / \mathrm{s}$ were taken into consideration. For $M$. aeruginosa, the detection of the highest cell abundances in the southernmost sampling points V2 and V3 were associated with winds blowing from the NW (Table 1), whereas those at the V1 and V4 sampling points were more surprisingly associated with winds from the SE. High cell abundances in the northern most sampling points V5 and V6 were equally associated with winds from NW and SE. For A. flos aquae, the results were more complicated, and no obvious link could be seen between the direction of the wind and the distribution of the cyanobacteria (Table 1). The same analyses were performed by taking into account the wind data one and two days before sampling (instead 5-10 hours before sampling), but no obvious relationship was detected (data not shown).

\subsection{Influence of the number of sampling points on the estimated cyanobacterial cell} abundances in the lake 
178 The cyanobacterial cell abundances in the shallow lake were estimated by calculating the 179 average value for the six sampling points (see Fig. 1). In order to determine the number of 180 sampling points required to obtain a good estimation of cyanobacterial cell abundances in the

181 lake, we compared the estimations of cell abundance based on using samples from just one, 182 two, three, four or five sampling points with that based on all six. To do this, we calculated

183 the correlation coefficients (Spearman) between the estimations based on the six sampling 184 points and those based on one to five sampling points for each species (Fig. 7). We considered 185 all possible combinations of points, and the results are classified in the figure on the basis of 186 increasing order of $r$ values within each combination of groups. For both species, we found

187 that the estimations of cell abundances based on only one or two sampling points were 188 generally rather badly correlated with those obtained using all six sampling points. On the 189 other hand, it appeared that good correlations (around or $>0.9$ ) were obtained when at least 190 three sampling points were used, but also that the variations due to the choice of the sampling 191 points was still considerable when only three sampling points were used.

192 In order to find out which combinations of sampling points provided the best results

193 when only two or three sampling points were used, we classified all the possible combinations 194 of points. To do this, we added the rank of each combination of sampling points obtained for 195 the two species (M. aeruginosa and A. flos-aquae). From Figure 8, we can see that the best 196 estimations obtained using only two or three sampling points were provided by combinations 197 in which the sampling points used were on the shore opposite to the prevailing wind direction 198 over the lake. 3.5 Diel variations in the subsurface cyanobacterial biomass in the lake

201 Finally, we carried out a 24-hour estimation of the variations in the total cyanobacterial 202 biomass in the subsurface water (20 cm depth) of the lake, at five sampling points using the 
BBE torch (A-E, see Fig. 1). As shown in Fig. 9, there was a steady fall in the cyanobacterial

204 biomass at all sampling points during the afternoon and evening, and conversely an increase

205 late at night and in the morning. Moreover, the differences in biomass between the five

206 sampling points were smaller during the night than during the day, as was the standard error

207 (three measurements per sampling point). A multidimensional scaling analysis performed on

208 the same values confirmed these observations, with all the night sampling times being

209 grouped together, whereas the sampling times during the day were much more scattered (Data

210 not shown).

\section{Discussion}

213 As far as we are aware, this is the first attempt to investigate the influence of sampling

214 strategies on the evaluation of spatial and temporal variations in cyanobacterial abundances in 215 shallow lakes, which constitute unstable and complex ecosystems. These lakes are used by 216 humans for numerous activities, including recreational activities and the supply of drinking

217 water, which makes the monitoring of cyanobacteria in such ecosystems of particular 218 importance, especially as part of the evaluation of the health risks linked to cyanobacterial 219 blooms and their toxins. Sampling strategy is also very important in the context of basic 220 studies, because the quality of sampling has a major impact on the quality of the final results. In this study, we found that the sampling frequency required to obtain a good estimation of the temporal evolution of the cyanobacterial abundance depends on the

223 blooming species, M. aeruginosa or A. flos-aquae. Twice-monthly or monthly sampling 224 provided good results for M. aeruginosa, whereas this was not often enough to monitor the 225 chaotic population dynamics of $A$. flos-aquae. These findings are in contradiction with the 226 recommendations of Codd et al. (1999), who proposed weekly or a twice-monthly sampling 
for species that do not form scum (A. flos-aquae for example), and more frequent sampling

228 for scum-forming species (such as M. aeruginosa), because they can display more rapid

229 changes in concentration. On the other hand, in agreement with these authors, our findings

230 also demonstrate that a reactive approach to cyanobacterial sampling is called for, and that

231 appropriate monitoring programs must be devised for each ecosystem based on what is known

232 about how these systems function. It is clear that sampling only once or twice a month can

233 lead to a very considerable under-estimation of cyanobacterial concentrations, and thus of the

234 health risks associated with the bloom. As a result, a weekly sampling frequency seems to be

235 required for cyanobacteria in small freshwater ecosystems.

236 Our data on the variability of the spatial distribution of cyanobacteria in the lake

237 indicate that at least three sampling points were needed to obtain a good estimation of the

238 abundance, based on a comparison with estimations based on six sampling points. It appeared

239 also that if only three sampling points are used, the choice of the location of these sampling

240 points is very important for the quality of the estimation. The most reliable results were

241 obtained using sampling points located on the opposite side of the lake shore to the main axis

242 of the wind direction, and that adding more sampling points reduces the impact of the choice

243 of the location of the sampling points. Such horizontal variability in the distribution of

244 cyanobacteria has been previously documented for many ecosystems, and also for many

245 cyanobacterial species. For example, in a recent study, Briand et al. (2009) showed that the

246 spatial distribution of M. aeruginosa in a large freshwater reservoir on a given date could vary

247 from $7.10^{3}$ cells $/ \mathrm{mL}$ to $2.10^{8}$ cells $/ \mathrm{mL}$, depending on the location of the sampling points in the

248 reservoir. Many factors and processes can influence the horizontal distribution of

249 cyanobacteria in a freshwater ecosystem. Among them, wind and surface currents seem to

250 have the greatest impact. For example, the distribution of Microcystis spp. in lake Taihu (see

251 the review paper of Qin et al., 2010) and in Lake Ontario (Hotto et al., 2007) is clearly 
252 influenced by both winds and currents. Similarly, Moreno-Ostos et al. (2009) have shown that

253 in a Spanish reservoir currents have a marked effect on the distribution of cyanobacteria, and

254 more globally on the phytoplankton community. In this study, we found that the horizontal

255 distribution of M. aeruginosa in the lake was influenced more by wind direction than that of

256 A. flos-aquae. This could be explained by the fact that M. aeruginosa colonies are located at

257 the surface of the lake at the end of the night, and thus are more subjected to the influence of

258 the wind than A. flos-aquae filaments, which are distributed over the entire water column. We

259 found also that two sampling points in the lake (V5 and V6) were less influenced by wind

260 direction that the others. This could be explained by the fact that these two sampling points

261 are protected from the influence of winds blowing from the NW by an embankment located in

262 the North part of the lake. Finally, we also demonstrated that in such a small lake, the impact

263 of wind occurred at the scale of a few hours, in contrast to the previous findings of Welker et

264 al. (2003) showing that the distribution of cyanobacteria was influenced by winds that had

265 been blowing one or two days earlier.

In addition to this variability in their horizontal distribution; the vertical distribution of

267 cyanobacteria was also variable. Indeed, during the $24 \mathrm{~h}$ for which we used the BBE Torch to

268 monitor the concentrations of cyanobacteria, we found that they were lower in the subsurface

269 layer early at night than during the day. The greatest variations in biomass were recorded

270 during the daytime, both at the scale of one sampling point when the three measurements

271 were compared, and at the scale of the five sampling points monitored during this study.

272 These findings also suggest that several sampling points are necessary to obtain an accurate

273 assessment of the cyanobacterial biomass and that integrated sampling of the first meter of the

274 water column reduces the variability in the estimation of the biomass due to the position of

275 cyanobacteria in the water column. This finding is consistent with data reported by Ahn et al.

276 (2008) showing that an integrated method was the most appropriate sampling method for 
Oscillatoria and Microcystis blooms. The causes of these variations in the position of cyanobacteria in the water column have been studied for different species. Several papers (Porat et al., 2001; Rabouille and Salençon, 2005; Rabouille et al., 2005; Visser et al., 2005; Walsby, 1994) have shown that migrations of cyanobacteria in the water column are probably due to the dynamics of the carbon-reserve metabolism, and are strongly influenced by light, temperature, and water mixing.

From all these findings, guidelines should be proposed for the monitoring of cyanobacteria in shallow lakes Codd et al. (1999) propose that the choice of sampling frequency and the choice of the number and location of the sampling sites should depend on the purpose of monitoring. For example, sampling near public bathing sites was recommended in freshwater ecosystems used for recreational activities. However, this strategy might generate data relevant only to the immediate vicinity of the bathing area, which do not reflect the global distribution of cyanobacteria in the lake. This is especially true when this distribution is very varied, and could make it difficult to prevent or manage blooms. On the basis of our findings, we proposed a different sampling strategy, which does not depend on the purpose of the monitoring. In order to minimize the cost of the cyanobacteria survey, twice-monthly sampling could be the norm for monitoring, but only if it is complemented by regular visual surveys. Changes in the appearance of the water (e.g. its color) between two successive dates would lead to an immediate increase in the sampling frequency. If it is not possible to carry out this visual survey, only a weekly sampling strategy can ensure that a sporadic cyanobacterial bloom is not missed. With regard to the number of sampling points, we found that at least three sampling points were necessary to obtain an accurate assessment of the cyanobacterial biomass (based on comparison with six sampling points). However, even when three sampling points were used, we found that the choice of the location of the sampling points was also very important (Fig. 8), even though the lake was fairly rectangular 
in shape and its perimeter small (around $1.3 \mathrm{Km}$ ). These findings suggest that for large lakes and also for lakes with a more complex shape, a large number of sampling points would be necessary to obtain a good estimation of the cyanobacterial abundance. Clearly such sampling is time consuming and expensive. One way to reduce these costs would be to collect a large number of samples and then pool equal volumes of these samples in the same flask, before

307 carrying out a single analysis. In this study, as in most of the monitoring programs performed 308 in small lakes, all samples were taken from the shoreline of the lake. This kind of sampling is suitable for small lakes, but it has been shown that for large lakes (Rogalus and Watzin, 2008) shoreline sampling may miss early warning signs of bloom development, and also lead to the overestimation of the concentration of microcystins, when compared to data obtained from

312 offshore samples. For bigger lakes, therefore, the sampling strategy must include offshore 313 samples.

Different programs worldwide are testing alternatives to water sampling for the 315 monitoring of cyanobacteria in freshwater ecosystems. Two main approaches have been 316 investigated. The first one is based on the use of remote sensing, which has long been in use 317 in marine ecosystems (see for example Bracher et al., 2009). In freshwater ecosystems, the 318 paper of Hunter et al. (2008) has shown the potential of high resolution images for the assessment of the spatial distribution of $M$. aeruginosa in a shallow eutrophic lake. However, 320 the cost of these images and the impact of meteorological conditions are limiting factors for 321 envisaging the use of this tool in routine cyanobacteria monitoring programs. One alternative, 322 lower-cost solution could be based, in the future, on the use of drones to take aerial 323 photographs of freshwater ecosystems, but these tools are still in development. Moreover, 324 they will be only useful for cyanobacterial species that live in the surface water of lakes. The second way of monitoring of cyanobacteria without sampling the water being 326 investigated is the use of buoys equipped with a variety of sensors, including, for example, a 
submersible spectrofluorometer to quantify the biomass of the cyanobacteria. This kind of

328 tool permits the real-time monitoring of phytoplankton, including cyanobacteria, as shown for example in the paper of Le $\mathrm{Vu}$ et al. (in press). The two obstacles to their use in routine cyanobacteria monitoring programs are the high price of these systems, and the fact that they only provide estimations for one sampling point. Despite this, the possible use of such buoys,

332 combined with the spatial monitoring of cyanobacteria by water sampling looks very

333 promising for surveying cyanobacteria in freshwater ecosystems.

\section{Conclusion}

335 The sampling of cyanobacteria in freshwater ecosystems is a hot topic, in particular in the 336 context of programs for surveying these toxic microorganisms in ecosystems used for the 337 production of drinking water or for recreational activities. Paradoxically, fewer studies deal 338 with the impact of sampling strategies on the estimation of cyanobacterial cell abundances in

339 freshwater ecosystems. In this study, we demonstrate that the choice of sampling strategy can 340 lead to very different estimations of the cell abundances of two blooming species in a shallow

341 lake and also that, depending on the cyanobacterial species involved, different sampling

342 strategies are required to obtain a good estimation of their population dynamics. All these

343 findings suggested that monthly or twice-monthly sampling strategies at just one sampling

344 point do not allow to provide an accurate estimation of cyanobacterial abundances, and thus

345 of the health risks associated with the presence of toxic species in aquatic ecosystems.

346 Moreover, although promising new technologies are being developed for monitoring

347 freshwater cyanobacteria, their cost and some other drawbacks mean that at present they

348 cannot replace water sampling, which will remain the basis of most of these monitoring 349 programs for the foreseeable future. 


\section{Acknowledgment}

352 This work was funded by the Région Rhône-Alpes and the Conseil Général de la Loire.

353 Monika Ghosh is acknowledged for improving the English version of the manuscript. The

354 comments and suggestions of the two anonymous reviewers were greatly appreciated.

355 


\section{References}

356 Ahn, C.Y., Joung, S.H., Park, C.S., Kim, H.S., Yoon, B.D., Oh, H.M., 2008. Comparison of

357 sampling and analytical methods for monitoring of cyanobacteria-dominated surface waters.

358 Hydrobiologia 596, 413-421.

359 Association Française de Normalisation, 2005. NF EN 15.204. Qualité de l'eau-Norme guide

360 pour le dénombrement du phytoplancton par microscopie inversé (méthode Utermöhl) T90379., AFNOR, La Plaine Saint Denis, France, 39 p.

362 Beutler, M., Wiltshire, K.H., Meyer, B., Moldaenke, C., Luring, C., Meyerhofer, M., Hansen,

363 U.P., Dau, H., 2002. A fluorometric method for the differentiation of algal populations in vivo 364 and in situ. Photosynthesis Research 72, 39-53.

365 Bracher, A., Vountas, M., Dinter, T., Burrows, J.P., Rottgers, R., Peeken, I., 2009.

366 Quantitative observation of cyanobacteria and diatoms from space using PhytoDOAS on

367 SCIAMACHY data. Biogeosciences 6, 751-764.

368 Briand, E., Escoffier, N., Straub, C., Sabart, M., Quiblier, C., Humbert, J.-F., 2009.

369 Spatiotemporal changes in the genetic diversity of a bloom-forming Microcystis aeruginosa 370 (cyanobacteria) population. The ISME Journal 3, 419-429.

371 Brient, L., Lengronne, M., Bertrand, E., Rolland, D., Sipel, A., Steinmann, D., Baudin, I.,

372 Legeas, M., Le Rouzic, B. Bormans, M. 2008. A phycocyanin probe as a tool for monitoring 373 cyanobacteria in freshwater bodies. Journal of Environmental Monitoring 10, 248-255.

374 Codd, G.A., Chorus, I., Burch, M., 1999. Design of monitoring programmes, in: WHO (Ed.), 375 Toxic Cyanobacteria in water: A guide to their public health consequences, monitoring and 376 management, E\&F Spon ed, London \& New York, pp. 302-316.

377 Codd, G.A., Lindsay, J., Young, F.M., Morrison, L.F., Metcalf, J.S., 2005. Harmful 378 cyanobacteria, in: Huisman, J., Matthijs, H.C.P., Visser, P.M. (Eds.), Harmful Cyanobacteria. 379 Springer, Dordrecht, pp. 1-23. 
Hotto, A.M., Satchwell, M.F., Boyer, G.L., 2007. Molecular characterization of potential

381 microcytsin-producing cyanobacteria in lake Ontario embayments and nearshore waters.

382 Applied and Environmental Microbiology 73, 4570-4578.

383 Hunter, P.D., Tyler, A.N., Gilvear, D.J., Willby, N.J., 2009. Using remote sensing to aid the

384 assessment of Human health risks from blooms of potentially toxic Cyanobacteria.

385 Environmental Science \& Technology 43, 2627-2633.

386 Hunter, P.D., Tyler, A.N., Willby, N.J., Gilvear, D.J., 2008. The spatial dynamics of vertical 387 migration by Microcystis aeruginosa in a eutrophic shallow lake: A case study using high 388 spatial resolution time-series airborne remote sensing. Limnology and Oceanography 53, $3892391-2406$.

390 Kuiper-Goodman, T., Falconer, I., Fitzgerald, J., 1999. Human health aspects, in: Chorus, I., 391 Bartram, J. (Eds.), Toxic cyanobacteria in water: a guide to their public health consequences, 392 monitoring and management. WHO, pp. 125-160.

393 Le Vu, B., Vinçon-Leite, B., Lemaire, B., Bensoussan, N., Calzas, M., Drezen, C., Deroubaix, 394 J., Escoffier, N., Dégrés, Y., Freissinet, C., Groleau, A., Humbert, J.-F., Paolini, G., Prévot, 395 F., Quiblier, C., Rioust, E., Tassin, B., in press. High-frequency monitoring of phytoplankton 396 dynamics within the European water framework directive: application to metalimnetic 397 cyanobacteria. Biogeochemistry.

398 Leboulanger, C., Dorigo, U., Jacquet, S., Le Berre, B., Paolini, G., Humbert, J.-F., 2002.

399 Application of a submersible spectrofluorometer for rapid monitoring of freshwater 400 cyanbacterial blooms : a case study. Aquatic Microbial Ecology 30, 83-89.

401 Markensten, H., Moore, K., Persson, I., 2010. Simulated lake phytoplankton composition 402 shifts toward cyanobacteria dominance in a future warmer climate. Ecological Applications $403 \quad 20,752-767$. 
404 Moreno-Ostos, E., Cruz-Pizarro, L., Basanta, A., George, D.G., 2009. Spatial heterogeneity of 405 Cyanobacteria and Diatoms in a thermally stratified canyon-shaped reservoir. International. 406 Review of Hydrobiology. 94, 245-257.

407 OCDE, 1982. Eutrophisation des eaux : méthodes de surveillance, d'évaluation et de lutte.

408 OCDE, 164 p.

409 Paerl, H.W., Huisman, J., 2009. Climate change : a catalyst for global expansion of harmful 410 cyanobacterial blooms. Environmental Microbiology Reports 1, 27-37.

411 Parsons, T.R., Strickland, J.D.H., 1963. Discussion of spectrophotometric determination of 412 marine-plant pigments with revised equations for ascertaining chlorophylls and carotenoïds. 413 Journal of Marine Research 21, 155-163.

414 Porat, R., Teltsch, B., Perelman, A., Dubinsky, Z., 2001. Diel buoyancy changes by the 415 Cyanobacterium Aphanizomenon ovalisporum from a shallow reservoir. Journal of Plankton 416 Research 23, 753-763.

417 Qin, B., Zhu, G., Gao, G., Zhang, Y., Li, W., Paerl, H., Carmichael, W., 2010. A drinking 418 water crisis in Lake Taihu, China: Linkage to climatic variability and lake management. 419 Environmental Management 45, 105-112.

420 R Development Core Team, 2010. R: a language and environment for statistical computing. R 421 Foundation for statistical computing, Vienna, Austria. ISBN 3-900051-07-0, URL 422 http://www.R-project.com.

423 Rabouille, S., Salençon, M.J., 2005. Functional analysis of Microcystis vertical migration: a 424 dynamic model as a prospecting tool. II. Influence of mixing, thermal stratification and 425 colony diameter on biomass production. Aquatic Microbial Ecology 39, 281-292.

426 Rabouille, S., Salençon, M.J., Thebault, J.M., 2005. Functional analysis of Microcystis 427 vertical migration: A dynamic model as a prospecting tool I - Processes analysis. Ecological 428 Modelling 188, 386-403. 
429 Rogalus, M.K., Watzin, M.C., 2008. Evaluation of sampling and screening techniques for

430 tiered monitoring of toxic cyanobacteria in lakes. Harmful Algae 7, 504-514.

431 Sabart, M., Pobel, D., Latour, D., Robin, J., Salençon, M.J., Humbert, J.-F., 2009.

432 Spatiotemporal changes in the genetic diversity in French bloom-forming populations of the

433 toxic cyanobacteria Microcystis aeruginosa. Environmental Microbiology Reports 1, 263-

434272.

435 Visser, P.M., Ibelings, B.W., Mur, L.R., Walsby, A.E., 2005. The ecophysiology of the

436 harmful cyanobacterium Microcystis - Features explaining its success and measures for its

437 control, in: Huisman, J., Matthijs, H.C.P., Visser, P.M. (Eds.), Harmful Cyanobacteria.

438 Springer, Dordrecht, pp. 109-142.

439 Walsby, A.E., 1994. Gas vesicles. Microbiological Reviews 51, 94-144.

440 Welker, M., Döhren von, H., Täuscher, H., Steinberg, C.E.W., Erhard, M., 2003. Toxic

441 Microcystis in shallow lakes Müggelsee (Germany) - dynamics, distribution, diversity. Archiv

442 für Hydrobiologie 157, 227-248.

443

444 
444 Table 1: Relationship between wind direction and high cell abundance recorded for 445 Microcystis aeruginosa and Aphanizomenon flos-aquae at the different sampling points. We

447 Fig. 1: Geographical location of the study site in France (left), and of the sampling points in 448 the lake (right)

Fig. 2: Changes over time of the concentrations of Microcystis aeruginosa (top) and Aphanizomenon flos-aquae (bottom). These concentrations were estimated by calculating the average cell count for the six samples at each date. The error bars indicate the standard deviation.

Fig. 3: Simulation of the change over time of Microcystis aeruginosa cell concentrations found using a weekly (top), twice-monthly (middle) or monthly sampling frequency (bottom), with lags for the first sampling day of zero days (-), 2 days (--) and 4 days (....) comparing to our first sampling day. The gray curve corresponds to the reference data.

Fig. 4: Simulation of the change over time of the biomass of Aphanizomenon flos-aquae 461 found using a weekly (top), twice-monthly (middle), or monthly sampling frequency 462 (bottom), and with lags for the first sampling day of zero days (-), 2 days (--) and 4 days (...) 463 comparing to our first sampling day. The gray curve corresponds to the reference data.

465 Fig. 5: Spatial distribution of two cyanobacteria, Microcystis aeruginosa and Aphanizomenon 466 flos-aquae, in the lake at four sampling dates (July, 9, 17 \& 23; August, 8) 
468 Fig. 6: Change over time in the coefficients of variation of the mean cell abundances of 469 Microcystis aeruginosa (black triangle) and Aphanizomenon flos-aquae (white square) 470 estimated at all six sampling points.

472 Fig. 7: Spearman correlation values between Microcystis aeruginosa (top) and 473 Aphanizomenon flos aquae (bottom) cell abundances estimated from the mean values for all 474 six sampling point values, and those estimated from only one, two, three, four or five of these 475 six sampling points.

477 Fig. 8: Location of the sampling points providing the best (left) and worst (right) estimations 478 of cyanobacterial cell abundances, compared to estimations based on six sampling points. We 479 give the combinations for two (top) and three (bottom) sampling points. The polar plot shows 480 the direction of the maximum daily wind speed during the study. The different line types 481 permit to distinguish the two best or the two worst combinations of sampling points, using 482 two or three sampling points.

484 Fig. 9: Cyanobacterial biomass in the subsurface water of the lake over a 24-hour period at 485 five sampling points ( point $\mathrm{A}$, $\square$ point $\mathrm{B}, \boldsymbol{\Delta}$ point $\mathrm{C}, \times$ point $\mathrm{D}$, and $\diamond$ point $\mathrm{E}$ ). The error 486 bars indicate the standard deviation.

489 Supplemental Figure 1. Distribution of the wind directions at the St-Etienne-Bouthéon 490 meteorological station during this study (June, 13 to October, 10, 2008). The curve and the 491 bars indicate respectively the mean speed and the occurrence per hour of the wind in each 492 direction. 
494 Supplemental Fig. 2. Evolution of the spatio-temporal distribution of Microcystis aeruginosa 495 (left) and Aphanizomenon flos aquae (right) in the lake during our study (the scale is the same 496 than in Fig. 5).

497

498 Supplemental Fig. 3. Relationship between the cell concentration and the coefficient of 499 variation for Microcystis aeruginosa (top) and Aphanizomenon flos-aquae (bottom) 